\title{
A micro-CT based study of the endocranial morphology of the Minatogawa I cranium
}

\author{
Daisuke $\mathrm{KUBO}^{1,2 *}$, Reiko T. $\mathrm{KONO}^{3}$, Gen SUWA ${ }^{2}$ \\ ${ }^{1}$ Department of Biological Sciences, Graduate School of Science, The University of Tokyo, Tokyo 113-0033, Japan \\ ${ }^{2}$ The University Museum, The University of Tokyo, Tokyo 113-0033, Japan \\ ${ }^{3}$ Department of Anthropology, National Museum of Nature and Science, Tokyo 169-0073, Japan
}

Received 20 January 2010; accepted 9 August 2010

\begin{abstract}
The Late Pleistocene fossil human remains (individuals I-IV) of Minatogawa, Okinawa Island are important in addressing the population history of the Japanese archipelago and in understanding evolution of Homo sapiens in eastern Asia. This study is the first on Minatogawa I's endocranial morphology, based on micro-computed tomography (micro-CT). We digitally reconstructed the Minatogawa I endocast, and created its physical model using a three-dimensional printer system. We compared the Minatogawa I endocast with available H. sapiens and archaic Homo endocasts. We found that Minatogawa I exhibits key derived endocranial features of $H$. sapiens, such as a highly elevated parietal, endocranial widening confined to a relatively anterior position, and a narrow internal occipital crest. The short, wide, and low proportioned Minatogawa I endocranium lies metrically at the margins of the modern human ranges of variation of this study. The Minatogawa I endocast exhibits a slightly underdeveloped frontal region with marked parasagittal ridges, a weak endocranial parietal boss, and a strong temporal bulge. It differs from Liujiang in the strong expression of these features as well as in overall metric proportions. A weak endocranial parietal boss and a strong temporal bulge are shared by Skhul V and Qafzeh 9, and may represent a primitive condition for H. sapiens in general.
\end{abstract}

Key words: endocranial morphology, Minatogawa, Late Pleistocene, micro-CT

\section{Introduction}

Paleontological survey and excavations at the Minatogawa limestone quarry fissure in southern Okinawa Island resulted in the discovery of human fossil remains including four partial skeletons in 1970-1971 (Suzuki and Hanihara, 1982). Because of associated extinct fauna and radiocarbon dates of $18250 \pm 650$ and $16600 \pm 300$ years BP obtained for charcoal fragments from the same lower levels of the fissure deposits that contained the partial skeletons, the Minatogawa skeletal remains have been considered to derive from the end of the Pleistocene (see Matsu'ura and Kondo, 2011, for further discussions).

The Minatogawa I cranium is known as the best preserved among the series, and has been studied by a number of researchers (e.g. Suzuki, 1982; Baba et al., 1998; Brown, 1999; Stringer, 1999). This cranium exhibits morphological features regarded as primitive, such as thick cranial vault bones, an inflated glabellar region, a deep temporal fossa, marked postorbital constriction, low position of maximum cranial breadth, and a rounded cranial outline in occipital view. In cranial metrics, Minatogawa I differs from modern

\footnotetext{
* Correspondence to: Daisuke Kubo, The University Museum, The University of Tokyo, 7-3-1, Hongo, Bunkyo-ku, Tokyo 113-0033, Japan.

E-mail: kubo@um.u-tokyo.ac.jp

Published online 25 November 2010

in J-STAGE (www.jstage.jst.go.jp) DOI: 10.1537/ase. 100120
}

East Asians in its low orbits and a relatively low and broad upper face (Suzuki, 1982; Hanihara, 1994; Brown, 1999). In these features and from other cranial metric and non-metric assessments, Minatogawa I has been considered to resemble the Holocene Jomon (Suzuki, 1982; Baba et al., 1998; Brown, 1999), the Liujiang cranium (Suzuki, 1982; Wu, 1992), or Wadjak 1 (Baba et al., 1998).

The cranial capacity of Minatogawa I was reported by Suzuki (1982) to be $1390 \mathrm{cc}$, but its endocranial structure and morphology has not been studied. Computed tomography (CT) and rapid prototyping technology (e.g. Zollikofer et al., 1998) enables a fuller access to endocranial morphology. We recently re-evaluated the cranial capacity of the Minatogawa I skull to be approximately $1335 \mathrm{cc}$ based on a high-resolution CT data set (Kubo et al., 2008). The purpose of the present study is to describe the endocranial morphology of the Minatogawa I cranium, and to examine its evolutionary significance. In particular, we examine the issue of whether Minatogawa I exhibits derived endocranial features of modern Homo sapiens or retains some primitive features of archaic Homo (in this paper, we use the term 'archaic Homo' for all taxa/specimens that are generally considered morphologically more primitive than 'anatomically modern' H. sapiens). We also address to what extent it is similar to Liujiang, another East Asian H. sapiens cranium often attributed to the Late Pleistocene, and considered to exhibit morphological affinities with Minatogawa I (Suzuki, 1982; $\mathrm{Wu}, 1992)$. A recent micro-CT based study suggested that Liujiang's endocast shares some primitive features with 
European Late Pleistocene H. sapiens (Wu et al., 2008). Finally, we attempt to provide some new insights on aspects of the Minatogawa I ectocranial form from an endocranial morphological perspective.

\section{Materials and Methods}

The Minatogawa I cranium was scanned by the microfocal X-ray CT system, TXS225-ACTIS (TESCO Co., Tokyo) at the University Museum, The University of Tokyo. The scanning parameters we used were $150 \mathrm{kV}$ tube voltage, $0.30 \mathrm{~mA}$ tube current, $0.380 \mathrm{~mm}$ slice thickness, and reconstructed pixel size of $0.380 \mathrm{~mm}$. A copper prefilter of $1.5 \mathrm{~mm}$ was used to reduce beam-hardening artifacts. A total of 543 serial slices were taken at $0.380 \mathrm{~mm}$ intervals. The volume data of the Minatogawa I cranium was reconstructed as a $512 \times 512 \times 543$ matrix of isotropic voxels of $0.380 \mathrm{~mm}$ size with 16-bit grayscale values.

A total of 38 modern adult male specimens (32 Japanese and one each of African, Australian, Buriat, European, Hawaiian, and Peruvian) were also scanned for comparisons. All crania are housed in the University Museum, The University of Tokyo. Since 27 of the 32 modern Japanese crania had their vault horizontally cut, we reattached the separated vault before scanning accounting for loss of bone at the plane of section. The scanning parameters we used for the modern crania were $130 \mathrm{kV}$ tube voltage, 0.24 or $0.30 \mathrm{~mA}$ tube current, $0.450 \mathrm{~mm}$ slice thickness and reconstructed pixel size of $0.450 \mathrm{~mm}$. Serial slices were taken at $0.450 \mathrm{~mm}$ intervals. A copper prefilter of $1.0 \mathrm{~mm}$ was used for the modern skulls.

We segmented the endocranial region first by half maximum height $(\mathrm{HMH})$ thresholding between the $\mathrm{CT}$ values of air and bone, and subsequently by slice-by-slice manual adjustment of bone-air boundaries. We used commercially available software Analyze 6.0 (Mayo Clinic, MN) and Avizo 5.0 (Mercury Computer Systems Inc., MA). The details of the segmentation procedure are given in Kubo et al. (2008). From the volume data, a polygon surface data set of the endocranial cavity (Figure 1) was extracted by the marching cube routine in Analyze 6.0. The extracted surface model of the Minatogawa I endocast consists of approximately 1.4 million polygons. We then analyzed the digital surface models using the software Rapidform 2006 (INUS technology, Inc., Seoul). We also produced plastic endocast models of Minatogawa I and a subset of modern human specimens, using a three-dimensional printer system (EDEN 260, Objet Geometries Ltd., MA). We find these physical models more useful in gaining three-dimensional morphological insights than digital models viewed on computer displays.

Our analysis included both qualitative and quantitative methods. The standard orientation adopted in this study for observations and measurements was determined in the following way. First, the midsagittal plane was defined as the plane containing foramen caecum, internal lambda, and opisthion. In Minatogawa I, opisthion is not preserved, and its proxy was taken at the anteriormost point remaining on the internal occipital crest. The frontal pole-occipital pole axis is commonly used as a horizontal reference, but this is not necessarily anatomically homologous among individuals (e.g. Hirschler, 1942). Therefore, we defined the horizontal plane as the plane that is orthogonal to the midsagittal plane and passes through the foramen caecum and another point that corresponds to the base of the posterior cerebrum. The procedure of determining the latter point is illustrated in Figure 2. In Minatogawa I, the anteroposterior axis defined here is almost parallel to the frontal pole-occipital pole axis of the right hemisphere.

In our quantitative evaluations, a series of endocranial measurements were made in order to clarify the dimensional characteristics of the Minatogawa I endocast. Definitions are shown in Table 1 and Figure 2. Measurements were made digitally on the surface model and recorded to the nearest $0.1 \mathrm{~mm}$. In order to enable comparisons with data available in the literature (see below), the endpoints of the variables height, cerebral height, frontal height, and frontal chord were determined in relation to the frontal pole-occipital pole horizontal (e.g. Wu et al., 2006). Besides the modern human comparative sample (see above), a broader range of fossil materials (listed in Table 2) were compared with Minatogawa I based on limited but widely available metrics in the literature.

We conducted principal components analysis (PCA) of Minatogawa I and 32 comparative specimens using a set of seven relatively well-defined metrics (greatest length, breadth, height, cerebral height, frontal height, frontal chord, and parietal chord). This was done in order to evaluate the general proportions of the Minatogawa I endocast against a broad comparative background. The comparative sample (Table 2) included 17 archaic Homo (Zhoukoudian II, V, X, XI, XII, Hexian, Trinil 2, Sambungmacan 3, Sangiran 2, 10, 12, 17, KNM-ER 3733, 3883, Daka, Salé, Kabwe), seven Late Pleistocene H. sapiens (Skhul V, Liujiang, Brno III, Předmostí III, IV, IX, X), and eight population examples of modern H. sapiens (African, Australian, Buriat, European, Hawaiian, Peruvian, modern Chinese mean (Wu et al., 2006), modern Japanese mean (this study)). As was done with Minatogawa I and our modern comparative specimens, data for Daka were taken from the micro-CT-based digital surface model (Gilbert et al., 2008), and that for Skhul V from the CT image set available at http://www.peabody. harvard.edu/node/446.

Four sets of principal components (PCs) were calculated, based on correlation and covariance matrices of either the raw metric or size-standardized (divided by the geometric mean) values. Principal component scores (PC scores) were calculated a posteriori for the modern Japanese specimens $(n=32)$, using the coefficients derived from the PCA of the comparative sample and Minatogawa I, and plotted to show the extent of individual variation within a single population. Calculations were conducted using the statistical environment R (R Development Core Team, 2008) and Excel (Microsoft Co., WA). We selected the PCs for interpretation by the following criteria. First, we extracted the PCs that cumulatively explained over $90 \%$ of the variance. Next, we checked for robustness of the PCs by calculating correlation coefficients (R) between the PCs derived from the correlation and covariance matrices. We interpreted only the PCs which corresponded well between the correlation and covariance matrix-based PCAs $(R>0.8)$. 

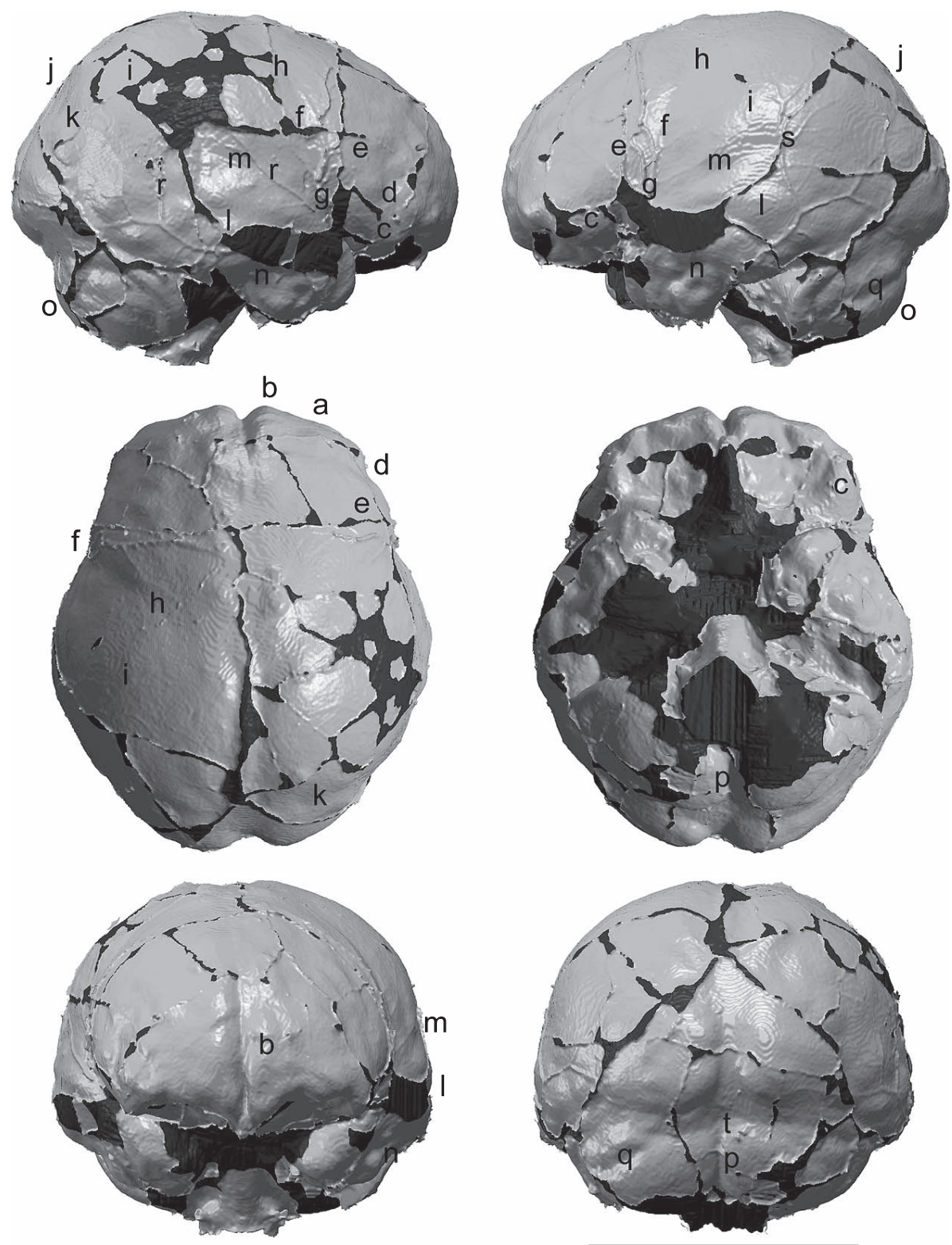

Figure 1. Endocranial model of Minatogawa I, viewed in perpendicular orientation relative to the orthogonal planes defined in this study (see text). The letters refer to the morphologies described in the text. In extracting the polygon surface model, we applied a blurring filter to the volume data in order to reduce the effects of 'stepping' caused by limitations of voxel resolution. The dark areas represent missing portions. The length of the scale bar is $10 \mathrm{~cm}$.

In our qualitative evaluations, we compared the Minatogawa I endocast with the modern human comparative sample (see above) and with a confined set of archaic Homo endocasts available to us for observation at the University of Tokyo or the National Museum of Nature and Science, Tokyo. These included adult examples of Neanderthals (Amud I and Neandertal), a Neanderthal child (TeshikTash) whose brain size is considered close to adult size (Ponce de León et al., 2008), and Asian Homo erectus (Zhoukoudian X, XI, and XII). We also made comparisons with Daka, an example of African H. erectus (Gilbert et al., 2008), and with other fossil specimens for which morphological descriptions are available in the literature (e.g.
Grimaud-Hervé, 1997; Holloway et al., 2004; and other references cited below). We also consulted information available on the endocranial morphology of two early Late Pleistocene $H$. sapiens skulls, Skhul V (McCown and Keith, 1939; http://www.peabody.harvard.edu/node/446 (CT image data)) and a preliminary report of the Qafzeh 9 endocast (Kondo et al., 2007).

\section{Results}

\section{Preservation}

A large part of the cranial base is missing: the cribriform plate, planum sphenoideum, sella turcica, dorsum sellae, the 

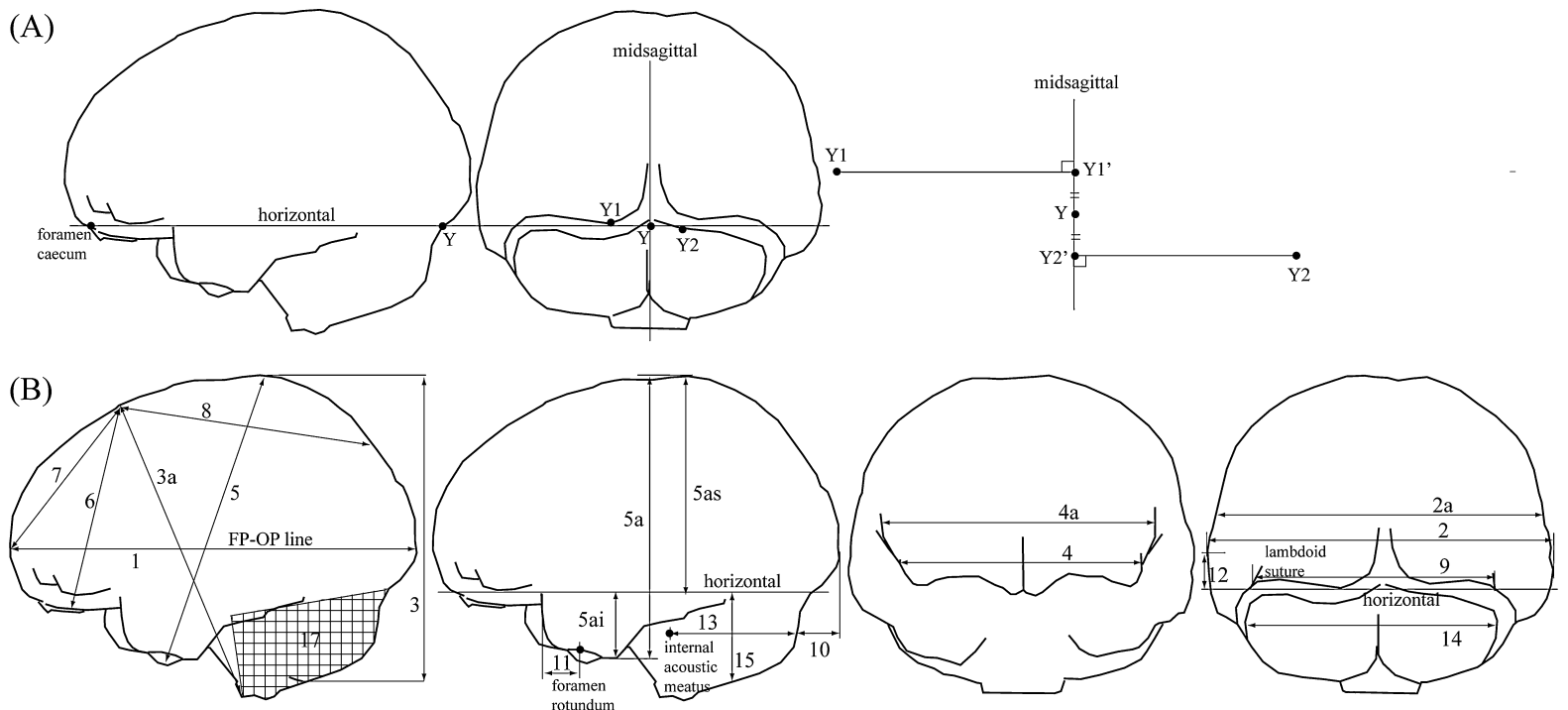

Figure 2. (A) The horizontal plane is defined as the plane that is orthogonal to the midsagittal plane and passes through the foramen caecum and another point Y, which corresponds to the base of the posterior cerebrum. Point Y is the midpoint between Y1' and Y2' (projected points from Y1 and Y2, respectively, onto the midsagittal plane). Y1 and Y2 are the posteroinferior-most point of the cerebral occipital surface and the posterosuperior-most point of the cerebellar surface, respectively. They are determined in the view where the cruciform eminence region of the endocast is oriented approximately perpendicular to the visual axis. (B) Measurements used in this study. The numbers correspond to the measurement items listed in Table 1.

medial part of the right greater wing, the right petrous, and the inferior part of posterior cranial fossa including the posterior margin of the foramen magnum. On the other hand, over half of the orbital roof and right lesser wing, left foramen rotundum, left foramen ovale, the opening of the left internal acoustic meatus, the clivus, the hypoglossal canals of both sides, and a large part of the internal occipital crest are preserved. The left lesser wing is broken, resulting in slight displacement between the anterior and middle cranial fossae. In addition, the posterosuperior part of the left temporal squama deviates slightly laterally from the adjacent parietal bone. The anterosuperior parts of the temporal squamae of both sides are missing, and a part of the right parietal bone is damaged. Aside from these larger damages, there are some slightly broken parts, including the posterolateral margin of the left petrous.

\section{Morphology}

Major dimensions and overall proportions

The endocast measurements of Minatogawa I and the modern Japanese specimens are shown in Table 3, together with the $z$-scores of the former. Bivariate plots of some of the widely available comparative measurements are shown in Figure 3. The Minatogawa I endocast is shorter, broader, and lower than typically seen in our modern human comparative sample. Each of the major dimensions (greatest length, $164.5 \mathrm{~mm}$ (left side); breadth, $140.4 \mathrm{~mm}$; height, $122.6 \mathrm{~mm}$ ) is within the current modern Japanese range, but the breadth-height index (87.3) is outside the modern Japanese range (2.0 standard deviation (SD) units below the modern Japanese mean). Relative endocranial breadth is large (length-breadth index, 85.8), 2.0 SD above the Japanese mean. Endocranial height above the horizontal plane (superior cerebral height, $86.8 \mathrm{~mm}$ ) is small, $2.1 \mathrm{SD}$ below the
Japanese mean. Vertical depth measures of the middle and posterior cranial fossae (PCF) below the horizontal plane are large (inferior cerebral height, $27.5 \mathrm{~mm}$; PCF height, $36.0 \mathrm{~mm}$ ).

Compared with other Late Pleistocene $H$. sapiens specimens, the greatest length of the Minatogawa I endocast is considerably short, while the breadth is comparable (Figure 3A). Of the Late Pleistocene $H$. sapiens cranium examined in this study, Skhul V shares a short frontal height and chord with Minatogawa I, but Liujiang, Brno III, and Předmostí do not (Figure 3B).

The endocranial volume of Minatogawa I $(1335 \mathrm{cc})$ is small, 1.4 SD below the modern Japanese mean, but within its range. This value is considerably smaller than that of Liujiang (1567 cc: Wu et al., 2008). The Minatogawa I endocast shows a combination of left occipital and right frontal petalia (further described below), a general pattern seen in the genus Homo (Holloway et al., 2004).

\section{Frontal endocranial morphology}

Predominance of the right frontal lobe is discernible by its greater fullness of the entire dorsal surface, although anterior protrusion of the frontal pole is about the same in both sides. As already mentioned, the frontal height of Minatogawa $\mathrm{I}$ is low $(83.8 \mathrm{~mm}), 2.3 \mathrm{SD}$ below the Japanese mean, and the frontal chord is also short $(71.3 \mathrm{~mm})$.

In Minatogawa I, the fullness of the frontal endocranial region seems weak for $H$. sapiens. In modern humans, the swelling formed by the entire anterior surface of the frontal lobe (hereafter referred to as frontal bulge) overhangs the anterior margin of the orbital surface, which leads to a rounded anterior outline of the endocast in superior or inferior views. Development of the frontal bulge of Minatogawa I is weaker laterally, which leads to a laterally receding (wedge-shaped) 
Table 1. Definition of measurements

\begin{tabular}{|c|c|}
\hline Number and name of measurements & Definition \\
\hline 1. Greatest length ${ }^{\S}$ & the straight distance between the frontal pole and the occipital pole (Ogawa et al., 1970). \\
\hline 2. Breadth ${ }^{\S}$ & $\begin{array}{l}\text { the transverse distance between the most laterally protruding points of the endocast, following Wu et al. } \\
\text { (2006). }\end{array}$ \\
\hline 2:1 Length-breadth index & breadth $(2) \times 100$ /greatest length $(1)$. \\
\hline 2a. Parietal width & the width of the endocast at the dorsal part to the temporal endocranial region. \\
\hline 2-2a. Temporal bossing & $\begin{array}{l}\text { breadth (2)-parietal width (2a). This is an indicator of lateral protrusion of the temporal region relative to } \\
\text { the parietal region. }\end{array}$ \\
\hline 3. Height ${ }^{\S}$ & $\begin{array}{l}\text { the height from the bottom of the posterior cranial fossa to the top of the endocast, following Wu et al. } \\
(2006) \text {. }\end{array}$ \\
\hline 3:1 Length-height index & height $(3) \times 100$ /greatest length $(1)$. \\
\hline $3: 2$ Breadth-height index & height $(3) \times 100 /$ breadth $(2)$. \\
\hline 3a. Basion-internal bregma height & $\begin{array}{l}\text { the straight distance between basion and internal bregma, the intersection of the coronal and sagittal } \\
\text { sutures on the endocranial surface. }\end{array}$ \\
\hline 4. Broca width & the width of the endocast at the lateral surface of the frontal caps. \\
\hline 4a. Frontal width & $\begin{array}{l}\text { the width of the endocast at the widest part of the coronal eminence, usually taken just caudal to the breg- } \\
\text { matic main ramus of the middle meningeal vessel. }\end{array}$ \\
\hline 2a-4a. Frontal narrowing & $\begin{array}{l}\text { parietal width ( } 2 a) \text {-frontal width ( } 4 a) \text {. This is an indicator of the narrowness of the frontal region relative } \\
\text { to the parietal region. }\end{array}$ \\
\hline 5. Cerebral height ${ }^{\S}$ & $\begin{array}{l}\text { the distance between the bottom of the middle cranial fossa and the top of the endocast, projected on the } \\
\text { midsagittal plane, following Wu et al. (2006). }\end{array}$ \\
\hline 5a. Vertical cerebral height* & the vertical length from the bottom of the middle cranial fossa to the top of the endocast. \\
\hline 5as. Superior cerebral height* & the vertical length from the horizontal plane to the top of the endocast. \\
\hline 5ai. Inferior cerebral height* & the vertical length from the horizontal plane to the bottom of the middle cranial fossa. \\
\hline 6. Frontal height ${ }^{\S}$ & $\begin{array}{l}\text { the distance from the internal bregma to the bottom of the frontal bec, projected on the midsagittal plane, } \\
\text { following Wu et al. (2006). }\end{array}$ \\
\hline 7. Frontal chord ${ }^{\S}$ & $\begin{array}{l}\text { the distance from the frontal pole to the internal bregma, projected on the midsagittal plane, following Wu } \\
\text { et al. (2006) }\end{array}$ \\
\hline 8. Parietal chord ${ }^{\S}$ & $\begin{array}{l}\text { the straight distance between the internal bregma and the internal lambda, the intersection of the sagittal } \\
\text { and lamboidal sutures on the endocranial surface, following Wu et al. (2006). }\end{array}$ \\
\hline 9. Occipital width & $\begin{array}{l}\text { the width of the endocast at the intersections of the lambdoidal suture and the superior edge of the relief of } \\
\text { the transverse sinus. }\end{array}$ \\
\hline 10. Occipital protrusion length* & the sagittal length from the posteriormost point of the cerebellar surface to the occipital pole. \\
\hline 11. $\mathrm{Te}$ & $\begin{array}{l}\text { the sagittal length from the lateral margin of the endocranial opening of the foramen rotundum to the ante- } \\
\text { riormost point of the middle cranial fossa. }\end{array}$ \\
\hline 12. Widest point height* & the vertical length from the horizontal plane to the most laterally protruding point of the endocast. \\
\hline 13. PCF len & $\begin{array}{l}\text { the sagittal length from the posterior edge of the opening of internal acoustic meatus to the posteriormost } \\
\text { point of the cerebellar surface. }\end{array}$ \\
\hline 14. Maximum cerebellar width & the width of the posterior cranial fossa excluding the sinus, following Holloway et al. (2004). \\
\hline 15. PCF height* & the vertical length from the horizontal plane to the bottom of the posterior cranial fossa. \\
\hline 16. Endocranial volume & the volume of the endocranial cavity. \\
\hline \multirow[t]{2}{*}{ 17. PCF volume } & $\begin{array}{l}\text { (1) Two landmarks are defined: landmark } X \text { is taken at the superior border of petrous bone in the parasag- } \\
\text { ittal plane where the posterior edge of the opening of internal acoustic meatus is located; landmark Y is } \\
\text { the point of the posterior cerebral base on the midsagittal plane used for the definition of the horizontal } \\
\text { plane (see the text). }\end{array}$ \\
\hline & $\begin{array}{l}\text { (2) Plane } \mathrm{A} \text { is defined as the plane acrossing } \mathrm{X} \text { and } \mathrm{Y} \text {, perpendicular to the sagittal plane. Plane } \mathrm{B} \text { is } \\
\text { defined as the plane acrossing } \mathrm{X} \text { and basion, perpendicular to the sagittal plane. The PCF volume is the } \\
\text { volume of the PCF region inferior to the plane A, and posterior to the plane B. }\end{array}$ \\
\hline 17:16 Relative PCF volume & PCF volume $(17) \times 100 /$ endocranial volume $(16)$ \\
\hline
\end{tabular}

Endopoints of the following metrics were determined in relation to the frontal pole-occipital pole line, following Wu et al. (2006): Height (3), Cerebral height (5), Frontal height (6) and Frontal chord (7).

* Metrics taken in reference to the horizontal plane adopted in this study (see the text).

$\S$ Metrics used in the principal component analysis with comparative fossil materials.

anterior outline in superior view (Figure 1a). This condition recalls those of archaic Homo (Weidenreich, 1939; Vlček, 1969; Ogawa et al., 1970) (Figure 4), although it is approximated in several individuals of the current modern human sample.

On the anterosuperior surface of the medial frontal lobe, parasagittal ridges (Figure 1b) are well developed just lateral to the frontal crest's groove. This feature is frequently well defined in archaic Homo (Falk et al., 2005; Gilbert et al., 2008), but weak in modern humans (Figure 4). Among Late Pleistocene H. sapiens, Brno III (e.g. Grimaud-Hervé, 1997) seems to exhibit a slightly wedge-shaped anterior outline in superior view, but the others, including Liujiang (Wu et al., 2008), exhibit a rounded outline more typical of modern H. sapiens. The Skhul V endocast does not show a wedgeshaped anterior outline or marked parasagittal ridges, but the frontal endocranial region is even flatter dorsoventrally than Minatogawa I. Qafzeh 9 seems indistinguishable from modern $H$. sapiens in its rounded frontal contour in both superior and lateral views (Kondo et al., 2007).

The frontal cap (Broca's cap) of Miantogawa I (Figure 1c, Figure 4) protrudes more strongly anteriorly and inferiorly 
Table 2. Source of metric data of human fossil endocasts

\begin{tabular}{ll}
\hline \multicolumn{1}{c}{ Specimen } & \multicolumn{1}{c}{ Reference } \\
\hline H. erectus & \\
O.H. 9, Ngandong 1, 6, 7, 11, 12 & Holloway et al. (2004) \\
Daka & Gilbert et al. (2008), present study \\
KNM-ER 3733, 3883, Trinil 2, Sangiran 2, 10, 12, 17, Sambungmacan 3, ZKD II, V, X, XI, XII, Hexian & Wu et al. (2010) \\
H. neanderthalensis & Ogawa et al. (1970) \\
Amud I & Trinkaus (1983) \\
Shanidar 1 & Ponce de León and Zollikofer (1999) \\
Le Moustier 1 & Holloway et al. (2004) \\
Neandertal, Gibraltar I, La Chapelle aux Saints, La Ferrassie I, La Quina V, Circeo I, Spy I, II & Bruner and Manzi (2008) \\
Saccopastore I & \\
African Middle/early Late Pleistocene archaic Homo & Holloway et al. (2004) \\
Jebel Irhoud I & Wu et al. (2008) \\
Kabwe & Wu et al. (2010) \\
Salé & \\
H. sapiens & present study \\
Skhul V & Wu et al. (2008) \\
Liujiang, Brno III, Předmostí III, IV, IX, X & \\
\hline
\end{tabular}

Table 3. Endocranial measurements of Minatogawa I and modern Japanese male specimens

\begin{tabular}{|c|c|c|c|c|c|}
\hline \multirow[b]{2}{*}{ Linear measurement $(\mathrm{mm})$ and volume $(\mathrm{cc})$} & \multicolumn{2}{|c|}{ Minatogawa I } & \multicolumn{3}{|c|}{ Modern Japanese male $(n=32)$} \\
\hline & & $\begin{array}{l}z \text {-score based on the } \\
\text { variation of the modern } \\
\text { Japanese specimens }\end{array}$ & Range & Mean & SD \\
\hline 1. Greatest length & 163.6 & -1.2 & $160.7-182.8$ & 169.9 & 5.4 \\
\hline 1. (left) & 164.5 & -1.0 & $160.6-184.8$ & 170.5 & 5.8 \\
\hline 1. (right) & 162.6 & -1.3 & $160.7-180.8$ & 169.3 & 5.2 \\
\hline 2. Breadth & 140.4 & +1.6 & $123.6-140.8$ & 132.9 & 4.7 \\
\hline $2: 1$ Length-breadth index & 85.8 & +2.0 & $72.0-87.3$ & 78.3 & 3.8 \\
\hline 2a. Parietal width & 129.3 & -0.1 & $120.7-137.2$ & 129.8 & 4.1 \\
\hline 2-2a. Temporal bossing & 11.1 & +4.0 & $0.0-7.4$ & 3.2 & 2.0 \\
\hline 3. Height (right) & 122.6 & -1.2 & $117.3-136.2$ & 128.0 & 4.4 \\
\hline $3: 1$. Length-height index & 74.5 & -0.3 & $69.2-80.1$ & 75.4 & 3.0 \\
\hline $3: 2$. Breadth-height index & 87.3 & -2.0 & $89.3-109.0$ & 96.4 & 4.5 \\
\hline 3a. Basion-internal bregma height & 126.9 & -0.6 & $121.5-137.9$ & 129.9 & 4.9 \\
\hline 4. Broca width & 98.3 & -0.3 & $93.3-105.2$ & 99.2 & 3.0 \\
\hline 4a. Frontal width & 112.4 & -1.9 & $111.2-129.0$ & 119.6 & 3.8 \\
\hline 2a-4a. Frontal narrowing & 16.9 & +1.7 & $2.5-18.4$ & 10.2 & 3.8 \\
\hline 5. Cerebral height (right) & 121.2 & -0.4 & $111.4-134.1$ & 123.3 & 5.5 \\
\hline 5a. Vertical cerebral height & 114.2 & -1.0 & $107.7-127.7$ & 118.9 & 4.6 \\
\hline 5as. Superior cerebral height & 86.8 & -2.1 & $86.0-102.8$ & 95.6 & 4.2 \\
\hline 5ai. Inferior cerebral height & 27.5 & +1.3 & $17.2-29.7$ & 23.2 & 3.4 \\
\hline 6. Frontal height (right) & 83.8 & -2.3 & $83.0-104.7$ & 95.3 & 5.0 \\
\hline 7. Frontal chord (right) & 71.3 & -1.2 & $64.0-84.2$ & 77.1 & 5.0 \\
\hline 8. Parietal chord & 103.1 & -0.6 & $94.8-119.0$ & 107.3 & 7.1 \\
\hline 9. Occipital width & 96.0 & +1.1 & $82.2-98.7$ & 91.1 & 4.5 \\
\hline 10. Occipital protrusion length & 14.5 & +0.4 & $8.9-20.1$ & 13.5 & 2.8 \\
\hline 10. (left) & 15.1 & +0.2 & $8.5-23.4$ & 14.3 & 3.4 \\
\hline 10. (right) & 13.9 & +0.4 & $5.9-17.5$ & 12.7 & 2.8 \\
\hline 11. Temporal pole length (left) & 14.2 & -1.2 & $13.1-19.0$ & 16.1 & 1.6 \\
\hline 12. Widest point height & 11.4 & -2.1 & $12.1-42.9$ & 27.0 & 7.5 \\
\hline 12. (left) & 16.0 & -1.0 & $8.1-45.3$ & 25.9 & 9.9 \\
\hline 12. (right) & 6.7 & -2.3 & $12.3-48.2$ & 28.0 & 9.2 \\
\hline 13. PCF length & 54.4 & -2.2 & $55.5-65.8$ & 60.0 & 2.6 \\
\hline 14. Maximum cerebellar width & 101.2 & -0.4 & $94.3-114.6$ & 103.2 & 4.6 \\
\hline 15. PCF height & 36.0 & +0.9 & $23.3-39.7$ & 33.2 & 3.3 \\
\hline 16. Endocranial volume & 1335 & -1.4 & $1249-1684$ & 1475.3 & 102.3 \\
\hline 17. PCF volume & 118 & -0.4 & $94.0-157.0$ & 122.9 & 12.9 \\
\hline 17:16 Relative PCF volume & 8.8 & +0.6 & $7.1-10.6$ & 8.3 & 0.9 \\
\hline
\end{tabular}

Measurements of length or height without annotations are the mean of both sides. 

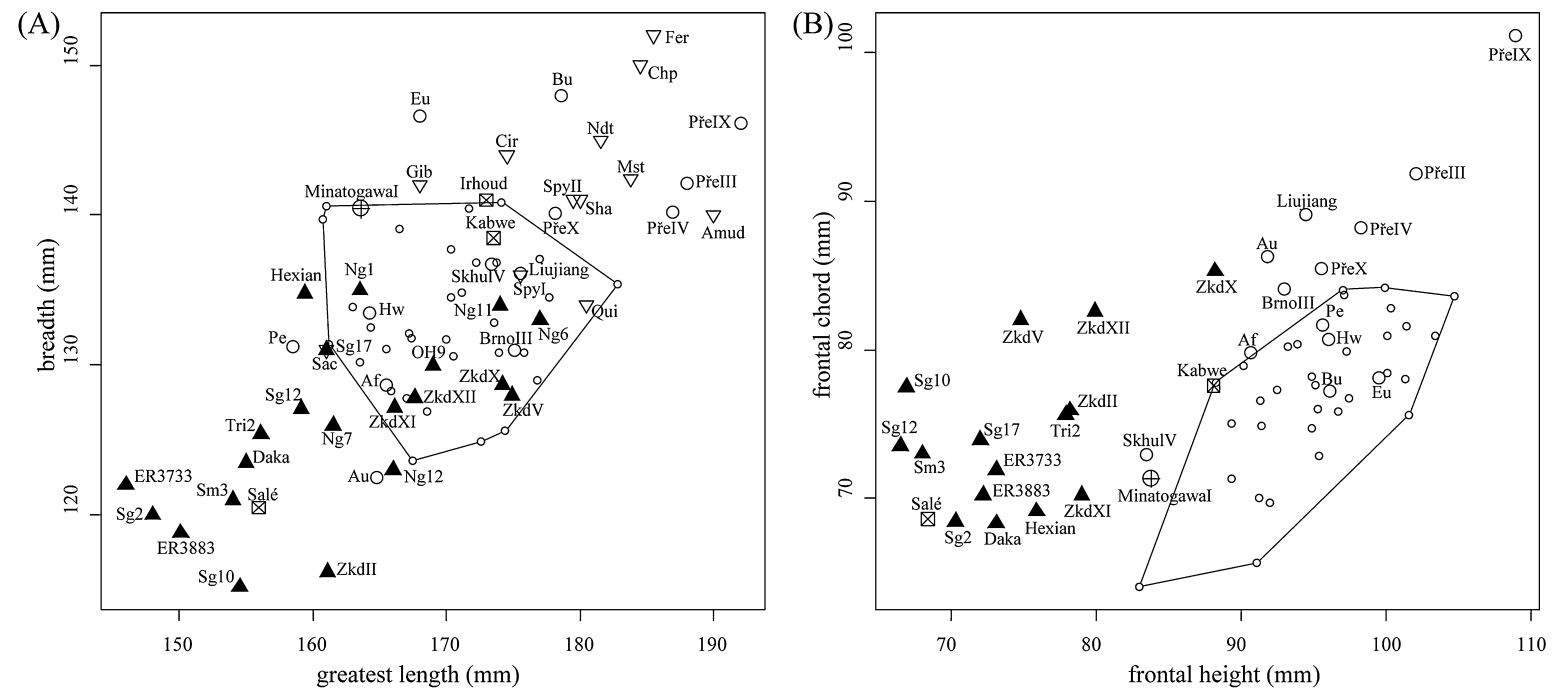

Figure 3. Bivariate plots of the endocranial measurements: (A) greatest endocranial length and breadth; (B) frontal height and frontal chord. Symbols are as follows: small open circle, modern Japanese specimens; large open circle, H. sapiens except for modern Japanese; square with cross, African Middle Late Pleistocene archaic Homo; open triangle, Neanderthals; and filled triangle, H. erectus. The H. sapiens specimens are: Af, African; Au, Australian; Bu, Buriat; Eu, European; Hw, Hawaiian; Pe, Peruvian; Brno III; Liujiang; Pře, Předmostí III, IV, IX, and X; Skhul V; and Minatogawa I. The African Middle Pleistocene archaic Homo specimens are: Irhoud, Jebel Irhoud 1; Kabwe; and Salé. The Neanderthals are: Amud I; Sha, Shanidar 1; Mst, Le Moustier 1; Ndt, Neandertal; Gib, Gibraltar I; Chp, La Chapelle-aux-Saints; Fer, La Ferrassie I; Qui, La Quina V; Cir, Circeo I, Spy I and II; and Sac, Saccopastore I. The H. erectus specimens are: KNM-ER 3733 and 3883; O.H. 9; Daka; Tri, Trinil 2; Sg, Sangiran 2, 10, 12, and 17; Sm, Sambungmacan 3; Ng, Ngandong 1, 6, 7, 11, and 12; Zkd, Zhoukoudian II, V, X, XI, and XII; and Hexian. The modern Japanese ranges of variation are shown as convex hulls.
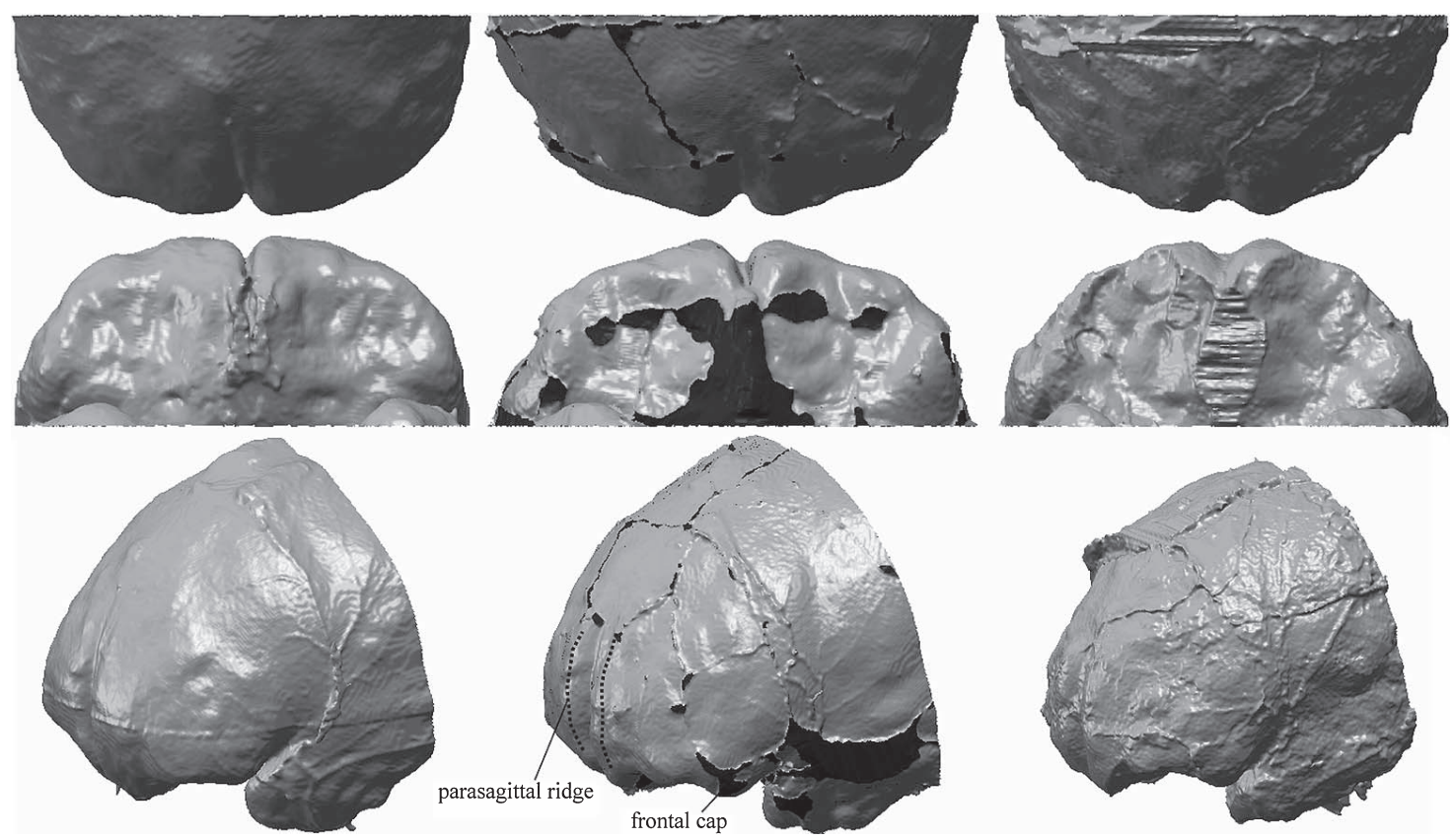

Figure 4. Comparison of the frontal part of the endocast of Minatogawa I with modern H. sapiens and archaic Homo. Superior (top), inferior (middle) and oblique view (bottom) of anterior frontal region. The frontal bulge in modern human specimen (left) is rounded and fully overhangs the anterior margin of the orbital surface. The outline of the Minatogawa I endocast (center) is less rounded, wedge-shaped in superoinferior view, and with well-developed parasagittal ridges dorsally near midline (indicated by dotted lines). The latter two features are reminiscent of the morphology seen in archaic Homo (right, African H. erectus Daka). The Minatogawa I's frontal cap protrudes more strongly anteriorly and inferiorly than typical in modern humans. 
than typical in the modern human sample, and is better developed on the left side. On the right side, a deep, vertically running groove (Figure 1d) incises the upper half of the frontal cap. The breadth of the endocast at the frontal cap (Broca width, $98.3 \mathrm{~mm}$ ) is comparable to the modern Japanese mean.

In the posterior part of the frontal region, where the coronal suture and the ascending ramus of the middle meningeal vessels are located, both archaic Homo and H. sapiens endocasts exhibit a moderate bulge, the 'coronal eminence' or 'coronal expansion' (Smith, 1928; Shellshear and Smith, 1934; Connolly, 1950). The coronal eminence of the Minatogawa I endocast (Figure 1e) is better developed on the right side, and a corresponding swelling is discernible on the ectocranial surface. The breadth of the endocast at the coronal eminence (frontal width, $112.4 \mathrm{~mm}$ ) is smaller than in the modern Japanese, and exhibits considerable narrowing relative to parietal width (frontal narrowing, $16.9 \mathrm{~mm}$ ).

\section{Parietal endocranial morphology}

The parietal chord $(103.1 \mathrm{~mm})$ is slightly shorter than the modern Japanese mean. Posterior to the coronal eminence, the Minatogawa I endocast is bilaterally constricted by strong depressions on both sides (Figure 1f). This depressed area extends posterosuperiorly from the Sylvian area (Figure 1g), forms a distinct "furrow" on the lateral surface of the endocast (Figure 1h), and finally disappears just lateral to a modest parasagittal eminence adjacent to the sagittal suture. A slight topographic depression is also discernible on the corresponding ectocranial surface. The presence of a depressed area posterior to the coronal eminence is not unusual in either archaic Homo or modern H. sapiens (Smith, 1928; Connolly, 1950). However, the other endocasts do not exhibit the bilateral constriction seen in Minatogawa I, because the depression is weaker, and mostly confined to the dorsal part of the endocast. The location of the depressed area corresponds to the approximate trajectory of the central sulcus, although Connolly (1950) suggested such endocast impressions to be independent of actual brain sulci patterns.

Posterior to the depressed area, the Minatogawa I endocast expands abruptly laterally and superiorly, and forms a distinct swelling (Figure 1i). This swollen area is full and rounded. However, as with the parietal boss of the ectocranial surface, this endocranial structure (hereafter referred to as endocranial parietal boss, or simply as 'parietal boss') of Minatogawa I is underdeveloped for a $H$. sapiens cranium. The breadth of the endocast at this location (parietal width, $129.3 \mathrm{~mm}$ ) is comparable to the modern Japanese mean. The Liujiang endocast, as judged from illustrations of $\mathrm{Wu}$ et al. (2008), also appears to exhibit a relatively weak parietal boss, although not as extreme as in Minatogawa I.

In lateral view, the endocast exhibits a steep declination (Figure 1j) from the vertex towards the occipital pole. This has been considered to be a derived feature of $H$. sapiens (Bruner, 2004). In addition, as with most of the modern specimens, Minatogawa I has no strong depressions at a dorsal position of the posterior parietal region, which has been observed in H. erectus (e.g. Gilbert et al., 2008) and African Middle Pleistocene archaic Homo (Smith, 1928).

\section{Occipital endocranial morphology}

The swelling formed by the entire posterior surface of the occipital lobe (hereafter referred to as occipital bulge) is significantly better developed on the left side: the left side bulge extends more inferiorly and medially and protrudes more posteriorly than the right side. On the right side, the occipital bulge is separated from the swollen area of the posterior parietal region by a slight depression (Figure 1k), located anterior to the lambdoid suture. Such a depression is not clear on the left side.

The occipital bulge of Minatogawa I appears full and rounded, but its posterior protrusion relative to the cerebellar surface (occipital protrusion length, $15.1 \mathrm{~mm}$ (left side), $13.9 \mathrm{~mm}$ (right side)) is comparable to that of the modern Japanese sample. The occipital width of Minatogawa I $(96.0 \mathrm{~mm})$ is slightly larger than the modern Japanese mean. Wu et al. (2008) suggested that the Late Pleistocene $H$. sapiens from Liujiang, Brno, and Předmostí retain a primitive condition (of archaic Homo) in having a large and posteriorly protruding occipital region, although $\mathrm{Wu}$ et al. (2010) later reported that some H. erectus examples (Sambungmacan 3, Trinil 2, KNM-ER 3733, 3883, and KNMWT 15000) lack strong occipital protrusion. Regarding the degree of occipital protrusion, both Minatogawa I and Skhul $\mathrm{V}$ (occipital protrusion length, $12.9 \mathrm{~mm}$ (left side), $15.0 \mathrm{~mm}$ (right side)) are metrically similar to the modern $H$. sapiens sample of the current study. Judging from published photographs (Holloway et al., 2004), European Late Pleistocene $H$. sapiens tends to exhibit an exaggerated posterior occipital projection. However, the degree of actual differences between these, Liujiang, and Minatogawa I needs to be carefully assessed metrically.

\section{Temporal endocranial morphology}

The Minatogawa I endocast is much wider in the temporal than in the parietal region (temporal bossing, $11.1 \mathrm{~mm}, 4.0$ SD above the Japanese mean). The widest point of the endocast is located at a relatively anterior position, above the petrous part of the temporal bone, and at a relatively low position compared with modern humans (widest point height, $16.0 \mathrm{~mm}$ (left side), $6.7 \mathrm{~mm}$ (right side)). This endocranial widening is caused by a strong swelling on the lateral surface of the posterior temporal region (hereafter referred to as temporal bulge) on both sides (Figure 11). The prominent temporal bulge relative to the parietal swelling results in the distinct 'furrow' along the superior border of the temporal region (Figure 1m). With respect to the fullness of the temporal bulge in Minatogawa I, we did not find any comparable example in the $H$. sapiens crania that we examined, although Skhul $\mathrm{V}$ exhibits a relatively strong lateral protrusion of the temporal endocranial region (temporal bossing, $7.4 \mathrm{~mm}, 2.1 \mathrm{SD}$ above the Japanese mean). Further anteriorly, at the inferolateral part of the middle cranial fossa, the temporal bulge disappears abruptly. Instead, juga cerebralia form strong depressions on the endocranial surface (Figure 1n).

Some previous studies (Vlček, 1969; Ogawa et al., 1970; Wu et al., 2010) indicated that, relative to the primitive condition of $H$. erectus, maximum endocranial breadth is located more anteriorly in $H$. sapiens, and more posteriorly in 
Neanderthals. We in part confirmed these observations. In our Neanderthal sample, maximum endocranial breadth was located more posteriorly than in the $H$. sapiens sample, but the difference between $H$. erectus and $H$. sapiens was not so obvious in the present data set. However, we observed that $H$. erectus and $H$. sapiens differ in extent and expression of temporal endocranial widening. In H. sapiens, the laterally projecting temporal surface extends dorsoventrally, and combines with a lack of a distinct Sylvian depression (Weidenreich, 1947). On the contrary, in our H. erectus sample, we observed an endocranial widening that continues posteriorly, forming an anteroposteriorly elongated lateral temporal swelling. The Minatogawa I endocast lacks both the Sylvian depression and the posterior elongation of the temporal bulge, as in modern $H$. sapiens.

A strong anterior protrusion of the temporal pole is a suggested derived feature of modern $H$. sapiens (Baba et al., 2003; Bastir et al., 2008). Measured relative to foramen rotundum position (temporal pole length, $14.2 \mathrm{~mm}$ ), the left temporal pole of Minatogawa I does not protrude anteriorly so strongly, but this seems to be affected by postmortem deformation. The same metric cannot be taken on the right side because of damage to the foramen rotundum area, but the undamaged right temporal pole is $6 \mathrm{~mm}$ more anterior than the left side. This indicates that temporal pole protrusion was probably stronger than apparent on the damaged left side.

\section{Posterior cranial fossa morphology}

The bulges formed by the cerebellar hemispheres (hereafter referred to as cerebellar bulge) (Figure 10) are rounded and approach each other towards the midline. The impression of the internal occipital crest is narrow and deep (Figure 1p), unlike the broad and blunt concavity observed in $H$. erectus, Neanderthals, and Middle Pleistocene archaic Homo (e.g. Seidler et al., 1997; Bräuer et al., 2004). On the left cerebellar surface, a groove for the possible horizontal sulcus is clearly discernible (Figure 1q).

In terms of metrics, the posterior cranial fossa of Minatogawa $\mathrm{I}$ is vertically large (PCF height, $36.0 \mathrm{~mm}$ ) but anteroposteriorly small (PCF length, $54.4 \mathrm{~mm}, 2.2 \mathrm{SD}$ below the Japanese mean). Its width and volume (maximum cerebellar width, $101.2 \mathrm{~mm}$; PCF volume, $118 \mathrm{cc}$; relative PCF volume, 8.8) are comparable to the modern Japanese means. Wu et al. (2008) suggested that Late Pleistocene H. sapiens from Liujiang, Brno, and Předmostí retain the primitive con- dition of archaic Homo in having a small and less globular cerebellar region. In light of wide variation seen in modern humans, the significance of PCF size/shape differences suggested between Minatogawa I and these Pleistocene specimens needs to be evaluated metrically by standardized methodology.

\section{Vascular impressions}

On the right side, both the anterior and posterior main branches of the middle meningeal artery give off the obelic (middle) ramus (Figure 1r), while on the left side, the obelic ramus is mainly derived from the posterior main branch (Figure 1s). A depression formed by the internal occipital protuberance (Figure 1t) is located at a position between the impression of the superior sagittal sinus and that of the left transverse sinus. This indicates that the superior sagittal sinus communicated with the right transverse sinus, while the left one communicated mainly with the straight sinus. The impression of the occipital sinus is not discernible.

\section{Principal component analysis (PCA)}

Table 4 and Figure 5 show the results of the PCA based on the correlation matrix, which was conducted to evaluate the general proportions of the Minatogawa I endocast in comparison with other H. sapiens or archaic Homo specimens. These results were largely duplicated in the PCA of the covariance matrix (data not shown).

In the PCA using raw values (Figure 5A), the PC1 explained $80.3 \%$ of the entire variance. It represents a general size factor, and contrasts the smaller $H$. erectus and larger $H$. sapiens specimens, especially Předmostí. Minatogawa I and two archaic Homo examples (Zhoukoudian X and Kabwe) occupied an intermediate position. The PC2 explained $8.2 \%$ of the variance. A high PC2 score is related with a relatively small breadth and long frontal chord. In the PC2 scores, archaic Homo and modern H. sapiens overlapped extensively. Liujiang, Brno III, Předmostí, and modern Australian had high PC2 scores, while Minatogawa I, Skhul V, modern European and Buriat had low PC2 scores.

In the PCA of the size-standardized values (Figure 5B and C), the PC1 explained $45.3 \%$ of the entire variance, and contrasted archaic Homo with modern H. sapiens. An archaic pattern in the PC1 score is related with relatively small height dimensions, short parietal chord, and relatively large frontal chord and greatest length and breadth. In PC 1 score,

Table 4. Factor loadings derived from the PCA based on the correlation matrix of the raw or size-standardized values

\begin{tabular}{|c|c|c|c|c|c|c|}
\hline & \multicolumn{2}{|c|}{ Raw values } & \multicolumn{4}{|c|}{ Size-standardized values } \\
\hline & PC1 & PC2 & $\mathrm{PC} 1$ & PC2 & PC3 & PC4 \\
\hline 1. Greatest length & 0.90 & 0.18 & -0.92 & -0.01 & -0.18 & 0.18 \\
\hline 2. Breadth & 0.84 & -0.36 & -0.68 & -0.42 & -0.41 & -0.37 \\
\hline 3. Height & 0.93 & -0.12 & 0.79 & -0.02 & -0.21 & 0.33 \\
\hline 5. Cerebral height & 0.95 & -0.09 & 0.45 & 0.12 & -0.78 & 0.15 \\
\hline 6. Frontal height & 0.95 & 0.03 & 0.76 & 0.41 & 0.13 & -0.47 \\
\hline 7. Frontal chord & 0.79 & 0.60 & -0.58 & 0.68 & 0.37 & 0.17 \\
\hline 8. Parietal chord & 0.89 & -0.17 & 0.34 & -0.72 & 0.54 & 0.12 \\
\hline Contribution (\%) & 80.3 & 8.2 & 45.3 & 19.3 & 18.3 & 8.1 \\
\hline
\end{tabular}

The above PCs were extracted first in the order of the contribution rate until they cumulatively explain over $90 \%$ of the variance, and then selected further based on the correlation to the PCs derived from the covariance matrix (the highest $R>0.8$ ). 

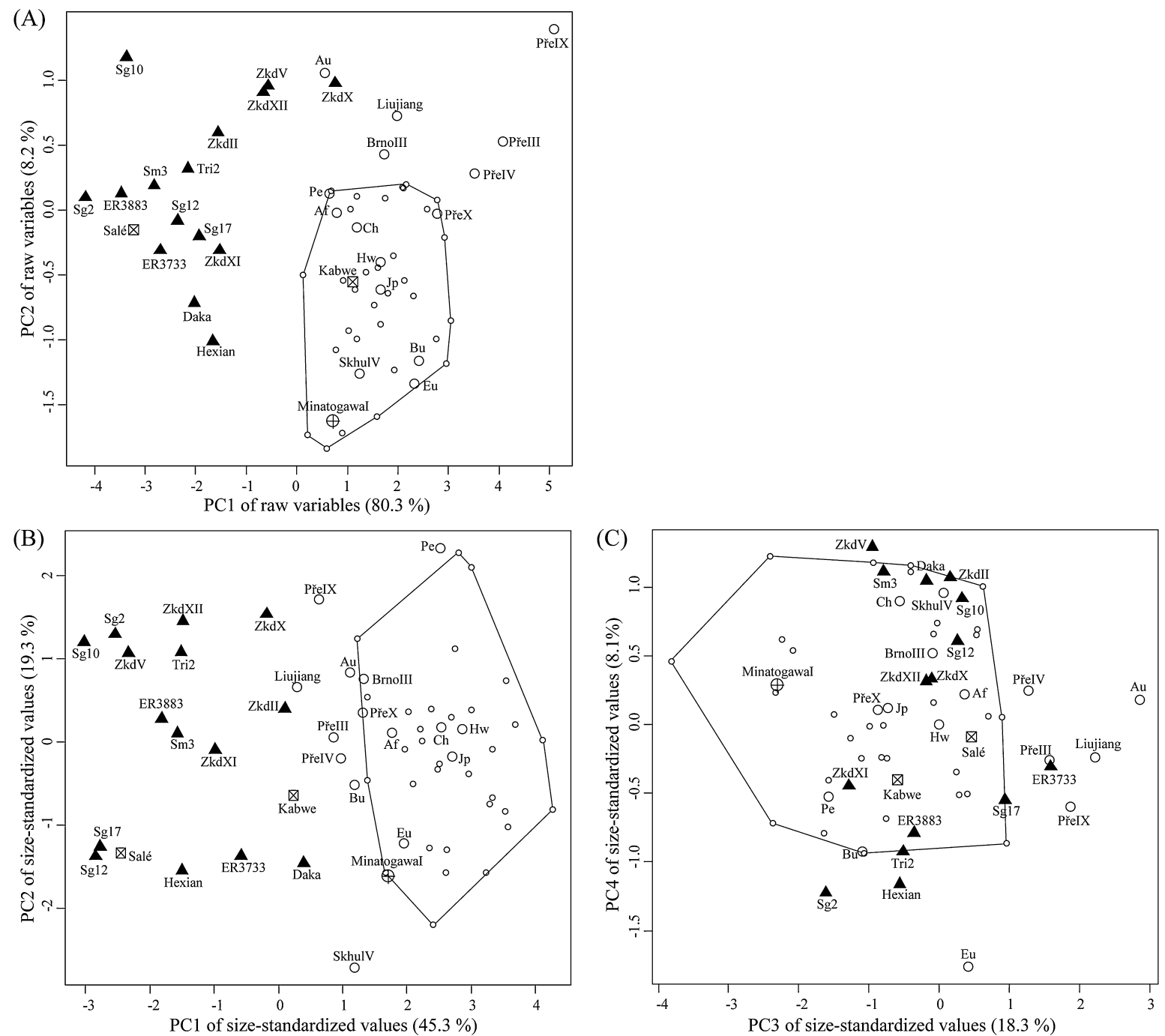

Figure 5. Summary plots of principle component analyses based on the correlation matrix of seven measurements expressing overall size and shape. First two or four PC scores are shown: (A) analysis of raw variables; (B, C) analysis of the size-standardized values. H. sapiens are represented by large open circle, African Middle Pleistocene archaic Homo by square with cross, and H. erectus by filled triangle. Abbreviations are as in Figure 2, with Ch and Jp representing the PC scores of the modern Chinese and Japanese mean. The PC scores of each modern Japanese specimen (small open circles) were calculated a posteriori. The modern Japanese ranges of variation are shown as convex hulls.

some Late Pleistocene $H$. sapiens, notably Liujiang, lies near the archaic Homo range, but Minatogawa I was not as close to archaic Homo as were the other Late Pleistocene examples. The PC2, PC 3 , and PC4 explained 19.3\%, 18.3\%, and $8.1 \%$ of the variance, respectively. In these PC scores, $H$. erectus and modern $H$. sapiens fully overlapped, although distinct shapes within $H$. sapiens tended to be expressed. In PC2, Minatogawa I and Skhul V shared low values (related with relatively large breadth, small frontal height, short frontal chord, and long parietal chord). In PC3, Minatogawa I had a low PC3 score (related with relatively large breadth, large cerebral height, short frontal chord and short parietal chord), in contrast to Liujiang which had a high PC3 score. In summary, the PCA results indicate that Minatogawa I shares aspects of overall endocranial proportions with Skhul $\mathrm{V}$, but differs from Liujiang, Brno III, or Předmostí.

\section{Discussion}

The Minatogawa I endocast is shorter, broader, and lower than typically seen in the modern Japanese sample. Although almost all of the individual endocranial metrics including cranial capacity were within the modern Japanese ranges of variation of this study, length-breadth and breadth-height indices exhibited extreme values due to its relatively broad, short and low endocranium. In particular, some of Minatogawa I's height measures were close to the smallest of the modern Japanese specimens. Despite such proportional differences from the modern Japanese, Minatogawa I exhibits some key derived characteristics of modern H. sapiens. These are: (1) the highly elevated parietal region with steep declination (in lateral view) from vertex towards the occipital pole; (2) endocranial widening confined to a relatively anterior position (above the petrous); and (3) the 
narrow internal occipital crest.

On the other hand, the frontal endocranial region is low and lacks the fullness typical of modern $H$. sapiens. The Minatogawa I endocast also has a few apparently rare or unique (among the specimens compared here) features such as the strong temporal bulge, weak parietal boss, and the clear bilateral constriction posterior to the coronal eminence. Minatogawa I's posterior cranial fossa volume is not small and the cerebellar surface forms strong spherical bulges, contrary to the condition suggested for Liujiang and European Late Pleistocene H. sapiens (Wu et al., 2008). However, variation in PCF size and shape within the current modern Japanese sample is considerable.

The PCA demonstrated that the Minatogawa I endocast is largely indistinguishable in its general proportions from those of the current modern sample. In these metrics, Minatogawa $\mathrm{I}$ is also more similar to Skhul V than to Liujiang. An additional difference between Minatogawa I and Liujiang is their size, a larger endocranial volume in Liujiang based primarily on greater length and a better developed frontal region. We further discuss below the distinctive features of the Minatogawa I endocast in an evolutionary context.

\section{Endocranial basis to aspects of Minatogawa I's external cranial shape}

Baba and coworkers (Baba and Narasaki, 1991; Baba et al., 1998; Baba, 2000) noted that the Minatogawa I cranium exhibits a Neanderthal-like rounded outline in occipital view due to a combination of features: the widest part of the neurocranium is located in a low position, there is a welldeveloped supramastoid crest, and the mastoid process is medially inclined. They regarded these features as primitive. However, the 'en bombe' morphology observed in Neanderthal crania is not necessarily primitive for Homo, but rather a derived feature considered to have evolved in the Neanderthal lineage (Nara, 1994; Dean et al., 1998). The primitive condition of archaic Homo is the 'en tent' form, which is unlike the morphology of the Minatogawa I neurocranium.

The rounded outline of the Minatogawa I cranium in occipital view can be attributed to the wide and low overall proportion of the endocast, the poorly developed endocranial parietal boss, and, in particular, the strong temporal bulge. This temporal bulge extends dorsoventrally, and is related to the anteriorly confined (above the petrous) endocranial widening. This differs from the primitive condition seen in $H$. erectus, in which endocranial widening continues posteriorly (see above), and in Neanderthals, in which the widest part of the endocast is located more posteriorly than in either $H$. erectus or H. sapiens (e.g. Vlček, 1969). Thus, it can be considered that the strong temporal bulge of Minatogawa I and its byproducts, such as the above-mentioned vault shape, are variants of the $H$. sapiens condition.

Among the $H$. sapiens comparative specimens that we examined, we found that Minatogawa I had an underdeveloped endocranial frontal region with relatively low height and weak 'fullness,' resulting in (1) weak overhang of the frontal bulge over the endocranial orbital surface; (2) an anterior frontal outline that recedes laterally in superoinferior view; and (3) well-developed parasagittal ridges. Ectocranially, this condition is reflected in its strongly receding frontal squama. However, despite the underdeveloped frontal region, breadth at the frontal cap was found to be comparable to the current modern Japanese mean. This indicates that the frequently referred to marked postorbital constriction of Minatogawa I (e.g. Baba et al., 1998; Brown, 1999) is not related to an absolutely narrow endocranial frontal region. The apparent constriction, then, must be related to a proportional difference of frontal breadth relative to more posterior endocranial and/or upper facial breadths. Alternatively, postorbital constriction is potentially affected by facial positioning relative to the neurocranium, which was not investigated in the present study.

\section{The Minatogawa I endocast compared with other Late Pleistocene examples}

Minatogawa I differs from modern and European Late Pleistocene (Holloway et al., 2004) H. sapiens examined in the present study in having a comparatively low and broad endocranial shape with strong temporal bulge, a weak parietal boss, and an underdeveloped frontal region. Liujiang shares with Minatogawa I an apparently weak parietal boss, albeit less extreme, but lacks a strong temporal bulge, and its frontal region is developed within ranges of modern $H$. sapiens (Wu et al., 2008). Wu et al. (2008) furthermore reported that Liujang and the Late Pleistocene European $H$. sapiens endocasts (Brno, Předmostí) differed from their modern Chinese sample in exhibiting posteriorly protruding occipital and small cerebellar regions. The Minatogawa I endocranium does not show these tendencies, although we note that occipital projection and posterior cranial fossa development need to be evaluated by methods comparable across specimens.

We find the limited information available for early Late Pleistocene H. sapiens (Skhul/Qafzeh) to be highly instructive in interpreting the significance of the Minatogawa I and Liujiang endocranial morphologies. Skhul V resembles Minatogawa I in having strong temporal bulges and somewhat underdeveloped endocranial parietal bosses. Qafzeh 9 seems to show this even more strongly (Kondo et al., 2007). These observations raise the possibility that both weak parietal boss and strong temporal bulge were common in at least some Late Pleistocene $H$. sapiens populations. If this was the case, these aspects of Minatogawa I's temporal and parietal endocranial morphology might represent retention of the ancestral condition from earlier Late Pleistocene $H$. sapiens.

Regarding frontal endocranial morphology, Skhul V and Qafzeh 9 (Kondo et al., 2007) resemble modern H. sapiens in lacking marked parasagittal ridges and having a rounded anterior contour in superior view. This indicates that the modern H. sapiens condition of endocranial frontal shape already existed by the early Late Pleistocene. If this was the case for Late Pleistocene $H$. sapiens in general, then the marked parasagittal ridges and laterally receding anterior contour seen in Minatogawa I may represent local or rare individual variation rather than a primitive retention from archaic Homo.

Finally, the Skhul V and Qafzeh 9 endocasts lack a strong occipital protrusion (McCown and Keith, 1939; Vlček, 1969; Kondo et al., 2007; present study), as is also the case 
in some African $H$. erectus specimens (Holloway et al., 2004; $\mathrm{Wu}$ et al., 2010). Therefore, the strong occipital protrusion reportedly shared by Liujiang, Brno, and Předmostí (Wu et al., 2008) is best interpreted as not primitive, but a derived variant within Late Pleistocene $H$. sapiens.

Wu et al. (2008) suggested that Liujiang's relatively small and weakly globular cerebellar region was primitive because this is shared by European Late Pleistocene H. sapiens and archaic Homo. Weaver $(2001,2005)$ hypothesized that cerebellar enlargement and reorganization might have occurred at around the terminal Late Pleistocene. We note here the uncertainty of Weaver et al.'s $(2001,2005)$ assumption that cerebellar volume can be meaningfully estimated from PCF size. Weaver $(2001,2005)$ estimated cerebellar volume of hominid fossil specimens by using the regression equation based on PCF volume of a mixed hominoid species sample (MRI data of 4 hylobatids, 13 great apes, and 17 modern humans). Although she justified her method by the high correlation between the two variables $\left(r^{2}=0.89\right)$, this was based on a cross-species size spread from gibbons to humans. We re-examined the datasets (Weaver, 2001, p. 242, Table A11) and found that correlation within the human sample $(n=17)$ is actually weak $\left(r^{2}=0.16\right)$ and not significant. The hypothesis presented by Weaver $(2001,2005)$ is therefore disputable, and we do not attempt to interpret PCF volume in relation to cerebellar volume, including that of Minatogawa I or Liujiang.

Further analyses with a more expanded comparative sample of Late Pleistocene $H$. sapiens (and Middle/Late Pleistocene archaic Homo), including new fossil evidence, are necessary to clarify these issues.

\section{Conclusions}

The Minatogawa I endocranium exhibits several derived features of $H$. sapiens such as an elevated parietal region, endocranial widening confined to a relatively anterior position, and a narrow internal occipital crest. Its overall shape (short, wide, and low) as expressed by standard linear metrics is also compatible with the modern $H$. sapiens condition, but occupies a marginal position relative to the modern Japanese ranges of variation. Compared with modern humans, the Minatogawa I endocast exhibits notable features such as an underdeveloped frontal region with marked parasagittal ridges and a combination of weak endocranial parietal boss and strong temporal bulge. Minatogawa I differs from Liujiang and Late Pleistocene European H. sapiens in these same features, as well as in overall metric proportions, a globular posterior cranial fossa, and lack of strong occipital protrusion, although a weak parietal boss is apparently seen also in the Liujiang endocast (albeit less extreme). A strong temporal bulge and weak parietal boss are seen in earlier Late Pleistocene H. sapiens (Skhul V and Qafzeh 9), and may represent a primitive condition for $H$. sapiens in general. Minatogawa I's rounded ectocranial contour in occipital view, a feature previously cited as a possible primitive retention from archaic Homo, is associated with Minatogawa's endocranial morphology and best interpreted as a variant condition of $H$. sapiens.

\section{Acknowledgments}

We thank Dr. O. Kondo (University of Tokyo) for providing literature and advice. We thank Drs. H. Baba, K. Shinoda, Y. Kaifu (National Museum of Nature and Science), and T. Nara (Nippon Dental University) for helpful comments, and Drs. D. E. Lieberman, O. Herschensohn and M. Morgan (Harvard University) for access to the Skhul V CT image data. This work was supported in part by the Grant-in-Aid for Scientific Research (S) from the Japan Society for the Promotion of Science (Project No. 17107006) and the Global COE Program (Integrative Life Science Based on the Study of Biosignaling Mechanisms) from MEXT, Japan.

\section{References}

Baba H. (2000) Physical adaptation of the Minatogawa people to island environments. Tropics, 10: 231-241.

Baba H. and Narasaki S. (1991) Minatogawa Man, the oldest type of modern Homo sapiens in East Asia. The Quaternary Research, 30: 221-230.

Baba H., Narasaki S., and Ohyama S. (1998) Minatogawa hominid fossils and the evolution of Late Pleistocene humans in East Asia. Anthropological Science, 106 (Supplement): 27-45.

Baba H., Aziz F., Kaifu Y., Suwa G., Kono R.T., and Jacob T. (2003) Homo erectus calvarium from the Pleistocene of Java. Science, 299: 1384-1388.

Bastir M., Rosas A., Lieberman D.E., and O'Higgins P. (2008) Middle cranial fossa anatomy and the origin of modern humans. The Anatomical Record, 291: 130-140.

Bräuer G., Groden C., Gröning F., Kroll A., Kupczik K., Mbua E., Pommert A., and Schiemann T. (2004) Virtual study of the endocranial morphology of the matrix-filled cranium from Eliye Springs, Kenya. Anatomical Record, 276A: 113-133.

Brown P. (1999) The first modern East Asians? Another look at Upper Cave 101, Liujiang and Minatogawa 1. In: Omoto K. (ed.), Interdisciplinary Perspectives on the Origins of the Japanese. International Research Center for Japanese Studies, Kyoto, pp. 105-131.

Bruner E. (2004) Geometric morphometrics and paleoneurology: brain shape evolution in the genus Homo. Journal of Human Evolution, 47: 279-303.

Bruner E. and Manzi G. (2008) Paleoneurology of an 'early' Neanderthal: endocranial size, shape, and features of Saccopastore 1. Journal of Human Evolution, 54: 729-742.

Connolly C.J. (1950) External Morphology of the Primate Brain. Charles C. Thomas, Springfield, IL.

Dean D., Hublin J.-J., Holloway R., and Ziegler R. (1998) On the phylogenetic position of the pre-Nandertal specimen from Reilingen, Germany. Journal of Human Evolution, 34: 485508.

Falk D., Hildebolt C., Smith K., Morwood M.J., Sutikna T., Brown P., Jatmiko, Saptomo E.W., Brunsden B., and Prior F. (2005) The brain of LB1, Homo floresiensis. Science, 308: 242-245.

Gilbert W.H., Holloway R.L., Kubo D., Kono R.T., and Suwa G. (2008) Tomographic analysis of the Daka calvaria. In: Gilbert W.H. and Asfaw B. (eds.), Homo erectus: Pleistocene Evidence from the Middle Awash, Ethiopia. University of California Press, Berkeley and Los Angeles, pp. 329-347.

Grimaud-Hervé D. (1997) L'Évolution de l'Encéphale chez Homo erectus et Homo sapiens: Exemples del'Asie et de l'Europe. CNRS Éditions, Paris.

Hanihara T. (1994) Craniofacial continuity and discontinuity of Far Easterners in the Late Pleistocene and Holocene. Journal of Human Evolution, 27: 417-441. 
Hirschler P. (1942) Anthropoid and Human Endocranial Casts. NV Noord-Hollandsche Uitgevers Maatschappij, Amsterdam.

Holloway R.L., Broadfield D.C., and Yuan M.S. (2004) The Human Fossil Record, Vol. 3: Brain Endocasts-The Paleoneurological Evidence. John Wiley \& Sons, Inc., Hoboken, NJ.

Kondo O., Fukumoto T., Fujimori T., Hishida H., Suzuki H., and Akazawa T. (2007) Kaseki-jinrui no nou: Neanderutāru-jin to sōki-gendaigata-shinjin no tōgai-endokyasuto-fukugen. Research Bulletin, Kochi University of Technology, 4: 13-22.

Kubo D., Kono R.T., Saso A., Mizushima S., and Suwa G. (2008) Accuracy and precision of CT-based endocranial capacity estimations: a comparison with the conventional millet seed method and application to the Minatogawa 1 skull. Anthropological Science, 116: 77-85.

Matsu'ura S. and Kondo M. (2011) Relative chronology of the Minatogawa and the Upper Minatogawa series of human remains from Okinawa Island, Japan. Anthropological Science, 119: 173-182.

McCown T.D. and Keith A. (1939) The Stone Age of Mount Carmel, Vol. 2: The Fossil Human Remains from the LevalloisoMousterian. Clarendon Press, Oxford.

Nara T. (1994) Étude de la variabilité de certains caractères métriques et morphologiques des Néandertaliens. Thèse de Doctorat, Université de Bordeaux I.

Ogawa T., Kamiya T., Sakai S., and Hosokawa H. (1970) Some observation on the endocranial cast of the Amud man. In: Suzuki H. and Takai F. (eds.), The Amud Man and His Cave Site. The University of Tokyo Press, Tokyo, pp. 411-424.

Ponce de León M.S. and Zollikofer C.P.E. (1999) New evidence from Le Moustier 1: computer-assisted reconstruction and morphometry of the skull. The Anatomical Record, 254: 474489.

Ponce de León M.S., Golovanova L., Doronichev V., Romanova G., Akazawa T., Kondo O., Ishida H., and Zollikofer C.P.E. (2008) Neanderthal brain size at birth provides insights into the evolution of human life history. Proceedings of the National Academy of Sciences of the United States of America, 105: 13764-13768.

R Development Core Team (2008) R: a language and environment for statistical computing. R Foundation for Statistical Computing, Vienna, Austria. http://www.R-project.org

Seidler H., Falk D., Stringer C., Wilfing H., Müller G.B., zur Nedden D., Weber G.W., Reicheis W., and Arsuaga J.L. (1997) A comparative study of stereolithographically modelled skulls of Petralona and Broken Hill: implications for future studies of middle Pleistocene hominid evolution. Journal of Human Evolution, 33: 691-703.

Shellshear J.L. and Smith G.E. (1934) A comparative study of the endocranial cast of Sinanthropus. Philosophical Transactions of the Royal Society of London, Series B, 223: 469-487.

Smith G.E. (1928) Endocranial cast obtained from the Rhodesian skull. In: Pyecraft W.P., Smith G.E., Yersley M., Carter J.T.,
Smith R.A., Hopwood A.T., Bate D.M.A., and Swinton W.E. (eds.), Rhodesian Man and Associated Remains. British Museum (Natural History), London.

Stringer C. (1999) The origin of morden humans and their regional diversity. Newsletter: Interdisciplinary Study on the Origins of Japanese Peoples and Cultures, 9: 3-5.

Suzuki H. (1982) Skulls of the Minatogawa man. In: Suzuki H. and Hanihara K. (eds.), The Minatogawa Man: The Upper Pleistocene Man from the Island of Okinawa. The University Museum, The University of Tokyo, Bulletin No. 19, pp. 7-49.

Suzuki H. and Hanihara K. (eds.) (1982) The Minatogawa Man: The Upper Pleistocene Man from the Island of Okinawa. The University Museum, The University of Tokyo, Bulletin No. 19, Tokyo.

Trinkaus E. (1983) The Shanidar Neandertals. Academic Press, New York.

Vlček (1969) Neandertaler der Tschechoslowakei. Academia. Verlag der Tschechoslowakischen Akademie der Wissenschaften, Prague.

Weaver A.G.H. (2001) The Cerebellum and Cognitive Evolution in Pliocene and Pleistocene Hominids. Dissertation, University of New Mexico, Albuquerque, NM.

Weaver A.H. (2005) Reciprocal evolution of the cerebellum and neocortex in fossil humans. Proceedings of the National Academy of Sciences of the United States of America, 102: $3576-3580$.

Weidenreich F. (1939) Six lectures on Sinanthropus pekinensis and related problems. Bulletin of the Geological Society of China, XIX: 1-111.

Weidenreich F. (1947) Some particulars of skull and brain of early hominids and their bearing on the problem of the relationship between man and anthropoids. American Journal of Physical Anthropology, 5: 387-427.

Wu X.J., Schepartz L.A., Falk D., and Liu W. (2006) Endocranial cast of Hexian Homo erectus from south China. American Journal of Physical Anthropology, 130: 445-454.

Wu X.J., Liu W., Dong W., Que J.M., and Wang Y.F. (2008) The brain morphology of Homo Liujiang cranium fossil by threedimensional computed tomography. Chinese Science Bulletin, 53: 2513-2519.

Wu X.J., Schepartz L.A., and Norton C.J. (2010) Morphological and morphometric analysis of variation in the Zhoukoudian Homo erectus brain endocasts. Quaternary International, 211: 4-13.

Wu X.Z. (1992) Origins and affinities of the stone age inhabitants of Japan. In: Hanihara K. (ed.), International Symposium on Japanese as a Member of the Asian and Pacific Populations. International Research Center for Japanese Studies, Kyoto, pp. $1-8$.

Zollikofer C.P.E., Ponce de León M.S., and Martin R.D. (1998) Computer-assisted paleoanthropology. Evolutionary Anthropology, 6: 41-54. 